\title{
Equity Sensitivity in "Fringe" Benefit Value and Satisfaction
}

\author{
Bart L. Weathington \\ The University of Tennessee at Chattanooga \\ Craig M. Reddock \\ Old Dominion University
}

\begin{abstract}
This study evaluated Equity Sensitivity (ES) as an explanation for individual differences in employee valuation and satisfaction with non wage employee benefits (i.e., fringe benefits) utilizing both the Equity Sensitivity Instrument (ESI) and Equity Preference Questionnaire (EPQ). ES proposes that individuals vary in their tolerance for inequity. It was hypothesized that individuals lower on the ES spectrum would more accurately estimate employer contributions toward benefits compared to individuals higher on the spectrum and individuals lower on the ES spectrum would be less satisfied with their benefits compared to those higher on the spectrum. Results found that individuals higher on the ES spectrum (i.e., those more tolerant of inequity) more accurately estimated their benefits and were also more satisfied with them. Additionally, the ESI and EPQ exhibited equivalent reliabilities though the ESI was found to have only one underlying dimension while the EPQ had four. Implications for management and directions for future research are discussed.
\end{abstract}

\section{Introduction}

Properly administered "fringe" benefits are an effective, albeit potentially expensive, way to attract and recruit employees (Messmer, 2006). The Bureau of Labor Statistics (2008) reports that over two-thirds of public and private employees can or do participate in a retirement plan and three-quarters of employees are eligible for medical benefits, with employers paying up to $83 \%$ of medical expenses for individuals and $71 \%$ for families. Benefits have been found to impact a number of outcomes in the workplace, including satisfaction and perceptions of justice (Arnold \& Spell, 2006). Accordingly, benefits are an important, though often overlooked, topic in applied psychological and management research.

Most employees do not know the true monetary value of their benefits and often greatly underestimate them (Wilson, Northcraft, \& Neale, 1985). This results in a loss of dollar utilization on the part of the employer because any money put toward benefits that is not recognized by the employee is money that could have been better invested elsewhere. Further complicating the study of fringe benefits is the finding that employees place differing amounts of importance on different benefits (Weathington \& Jones, 2006; Weathington \& Tetrick, 2000). 
One potential explanation for this discrepancy is equity theory (Adams, 1965), which states that individuals view their relationships with other people and organizations in terms of a transaction, and an inequity in this transaction can cause a variety of outcomes. Specifically, when an inequity in inputs and outputs is perceived, an individual may attempt to establish equality by putting forth less effort, attempting to get more output (e.g. asking for a raise) or by changing their perceptions regarding the inequality so that it is no longer regarded as such. Equity Sensitivity (ES), which accounts for individual differences under equity theory (Blakely, Andrews, \& Moorman, 2005; Miles, Hatfield, \& Huseman, 1989; 1994), posits that individuals vary in their preference for equity. It could be that differences in benefit importance are partially explained by where an employee falls on the ES continuum. It is possible that satisfaction/dissatisfaction with benefits could be both a function of inaccurate estimations of cost and ES typology.

\section{Benefits Valuation}

Employees' perceptions of their benefits can impact employee attitudes toward the workplace (Arnold \& Spell, 2006; Weathington \& Tetrick, 2000). Further, aspects of the organizational environment influence benefit satisfaction. For example, Arnold and Spell found that quality of benefit and satisfaction with benefit cost are positively related to perceptions of the fairness of the processes used to allocate resources and settle disputes (e.g., procedural justice). However, employees do not always realize the true monetary value of their benefits (Weathington \& Jones, 2006; Wilson et al., 1985). Employers may view benefits from a bottom-line objective perspective and take into account factors that employees usually do not consider. For example, employees typically pay far less for their benefits through work than they would if they purchased them as individuals. Also, although future legislation may change this, historically employees are often not taxed on the money that employers contribute to benefits. Given the amount of money that an employer puts towards employee benefits, "employers presumably expect a high valuation of benefits by employees to justify the compensation cost" (Wilson et al., 1985, p. 310). Thus, any difference between actual money contributed and perceived money contributed is money lost. Since some information regarding the monetary cost of benefits to an employee is presented as an itemized deduction with every paycheck the monetary cost of benefits is highly visible. The amount contributed by employers, however, is often not as easy for employees to view.

Another complicating issue is that employees value specific benefits differently. For example, Weathington and Tetrick (2000) found that the effect of benefit perception on affective commitment and economic satisfaction depends on employees' perception of whether or not a specific benefit is viewed as an "entitlement." Put another way, if an employee perceives a benefit to be a fundamental part of the overall compensation package that is "owed" to employees by the organization, then taking that benefit away will have a more significant negative impact on benefit satisfaction than if a non-entitled benefit is taken away. Additionally, Weathington, and Jones (2006) state that "the 
influence of a benefit on employee attitudes depends on perceptions of both the monetary and nonmonetary worth of the benefit" (p. 296). They found that, as the cost of a benefit goes up, often so does an employee's satisfaction with that benefit, regardless of how much they value it. Additionally, some benefits are viewed in monetary terms and others in non-monetary terms (Weathington, 2008; Weathington \& Jones). These findings imply that benefit value is a complex function of cost, attractiveness, and perception.

\section{The Equity Sensitivity Spectrum}

Adams' (1965) Equity theory states that individuals assess the ratio of outputs to inputs using a comparative standard; be it the individual him/her self or someone else in the work environment. If an inequity is perceived, then actions are taken (behaviorally or cognitively) by the person to address this inequity. If, for example, an employee perceives that he or she is putting forth a great deal of effort but that pay is not commensurate with this effort, then he or she will look for a way to eliminate this discrepancy. The employee could do this by asking for a raise, putting forth less effort, changing his or her cognitive perception of the discrepancy in a way that reduces it, or changing the comparative standard. Support for this theory in the workplace has been mixed, with most researchers attributing contradictory findings to the lack of consideration for individual differences, such as perceptions of equity (Miles et al., 1994).

To rectify this, Miles et al. (1989) hypothesized that there are three typological personalities directly linked to perceptions of equity based on an individual's sensitivity to equity: benevolents, sensitives and entitleds (Blakely et al., 2005; Miles et al., 1989; Miles et al., 1994). Benevolents tolerate situations where their input/outcome ratios are less than that of their comparative standard. Equity sensitives are directly in line with the tenets of equity theory, preferring their input/outcome ratios to match other peoples' ratios. Finally, entitleds prefer that their input/outcome ratios be greater than those of their referent. Allen and White's (2001) study of under-reward situations presents additional support that these three typologies are in fact distinct groups. These ratio preferences are based in part on an individual's particular outcome preference, specifically, whether an individual prefers interpersonal or monetary rewards (Miles et al., 1994). For example, benevolents appear to be more concerned about relationships than money, while the opposite is true for entitleds. Specifically, entitleds place significantly more importance on pay, fringe benefits, job security, and promotion and advancement than benevolents. Conversely, benevolents place more importance on a sense of accomplishment, doing meaningful work, doing challenging work, a feeling of personal worth, and a feeling of achievement. These preferences have clear implications for the impact of rewards, with entitleds showing an obvious preference for extrinsic tangible rewards, while benevolents prefer intrinsic ones. Equity sensitives appear to value tangible and intrinsic outcomes equally. This suggests that while all three ES types have an equal desire for equitable outcomes, they may differ in their preference for specific types of rewards (tangible vs. intangible; Miles et al., 1994). 
The outcome preferences of benevolents and entitleds seem theoretically related to Herzberg's Motivation-Hygiene theory (Herzberg, 1966), which posits that there are two distinct sets of factors, each serving a basic human need, that can cause individuals to be satisfied or dissatisfied with their jobs. The first set, factors internal to the individual that contribute to job satisfaction (e.g. motivating factors), include achievement, recognition, work itself, responsibility and advancement. Conversely, the second set of factors in the Motivation-Hygiene theory (MHT) are those that prevent job dissatisfaction (e.g. hygiene factors). These factors are external to the individual and include company policy and administration, supervision, salary, interpersonal relations and working conditions. Herzberg contends that the first set of factors serve a basic need to grow psychologically, while the second set satisfy an individual's need to avoid pain. The implication of this is that an organization must be mindful of both sets of factors - those that can increase job satisfaction and those that can maintain it - to ensure employees are satisfied.

There appears to be a similarity between the outcome preference of benevolents and motivating factors, as well as between the outcome preference of entitleds and hygiene factors. For example, benevolents seem concerned with more internal rewards, such as recognition and achievement. Conversely, entitleds prefer more external outcomes, such as monetary rewards. This theoretical overlap between ES theory and Herzberg's MHT is important in that it further illustrates the distinction between entitleds and benevolents regarding their preference for specific reward type. The overlap between ES and MHT seems particularly relevant to benefit perception especially given Weathington and Tetrick's (2000) proposition that "owed" benefits may have a negative impact on employee attitudes when absent (similar to hygiene factors); while benefits that are not seen as "owed" have their impact when present (similar to motivating factors).

There is, however, more to ES typologies than outcome preference. Yamaguchi (2003) and Allen, Takeda and White (2005) found that there are cross cultural differences, and Yamaguchi found that dispositional and attitudinal factors impact ES as well.

Additionally, ES typologies appear to moderate the relationship between organizational justice perceptions and organizational citizenship behaviors. Greenberg (1987) defines organizational justice as individuals' or employees' perception of whether or not they are being treated fairly by their organization. Blakely et al. (2005) found that benevolents perform significantly more organizational citizenship behaviors than entitleds when organizational justice is low; but when organizational justice is high, benevolents perform only slightly more organizational citizenship behaviors than entitleds.

Finally, ES appears to be related to behaviors after a psychological contract has been violated. According to Rousseau (1989), a psychological contract is an individual's belief that there is a "reciprocal obligation between the individual and the organization" ( $p$. 121) such that each has a certain set of expectations regarding how the individual should be treated and how they should in turn treat the organization. Restubog, Bordia, and Tang (2007) found that ES orientation appears to be a moderator in situations where psychological contracts have been broken; entitleds demonstrate stronger 
negative reactions to breaches of psychological contracts, engaging in more socially deviant acts than benevolents and sensitives.

Taken together, these findings demonstrate that ES is more than just a ratio of inputs to outputs and that one' position on the ES spectrum may impact how they view and react to a variety of organizational issues. Thus, the design of incentive/compensation programs in organizations may be improved if ES typology is taken into consideration.

\section{Fringe Benefits and Equity sensitivity}

Given the impact of benefits on a number of organizational outcomes and the emergence of equity sensitivity as a means of understanding individual differences with respect to organizational outcomes, combining these two discrete literatures may result in a better understanding of the employee-organization relationship. Because entitleds seem to be "keeping score" more than benevolents, ES may also impact how accurately employees estimate their employer's monetary contribution towards his or her benefits and how satisfied an employee is with his or her benefits. Conceptually, entitleds are concerned with getting more than they are giving in social exchanges. Accordingly, it may be the case that they pay close attention to how much money their employer pays towards their benefits. Based on this reasoning the following hypotheses are proposed:

Hypothesis 1: Individuals higher on the ES spectrum (e.g. benevolents) will be more inaccurate in their estimates of what their employer is contributing to their benefits than individuals lower on the spectrum (e.g. entitleds).

Hypothesis 2: Individuals lower on the ES spectrum will be less satisfied with their benefits than individuals higher on the spectrum.

\section{$\underline{\text { Issues in Equity Sensitivity Measurement }}$}

Several studies have assessed the reliability and validity of scales purported to measure ES (Foote \& Harmon, 2006; Wheeler, 2007). Currently, there are two commonly used measures of ES: the Equity Sensitivity Instrument (ESI), developed by Huseman et al. (1985) and the Equity Preference Questionnaire (EPQ), developed by Sauley and Bedeian (2000).

The ESI consists of five pairs of statements, with a subject being forced to distribute ten points between each pair of statements. The points are then summed to determine an individual's ES; a higher score indicating benevolence and a lower score indicating entitlement (Foote \& Harmon, 2006; Huseman, et al., 1985; Wheeler, 2007). The ESI has been criticized for several reasons, calling into question its robustness as a measurement of ES. Sauley and Bedeian (2000) have criticized it as being context dependent, and developed the Equity Preference Questionnaire (EPQ) to address these concerns. Also, Yamaguchi (2003) contends that "a forced distribution measure is not appropriate for measuring psychological states" (p. 331). Further, some researchers view the construct as simply being a continuum with entitleds on one end and 
benevolents on the other (Allen, Biderman, \& White, 2003; Restubog et al., 2007; Sauley \& Bedeian) and unfavorably view trichotmizing the construct as the ESI does. Researchers (see Sauley \& Bedeian; Yamaguchi), however, have proposed methodologies that modify the ESI to address the forced distribution and trichotomization issues.

Sauley and Bedeian (2000) developed the EPQ as an alternative measure of equity sensitivity. This scale consists of 16 Likert-type scale items which, like Miles et al.'s (1985) measure, attempts to determine an individual's equity typology. However, the EPQ has also been criticized. Specifically, Foote and Harmon (2006) found that the EPQ demonstrated unacceptable internal reliability, is not a unidemensional scale, and ultimately is a poor measure of ES.

Perhaps the most troubling findings regarding both ES measures are that studies comparing the two often come up with contradictory findings. For example, Wheeler (2007) found a significant correlation (0.60) between the ESI and the EPQ. However, Foote and Harmon (2006) found non-significant correlations (0.11 and -0.04, respectively) for student and non-student samples who took both the ESI and EPQ, as well as finding that the EPQ is multidimensional and that there are differences between student and nonstudent samples. Taken together, the disparate findings for both the $\mathrm{ESI}$ and EPQ indicate much is still unclear regarding their usefulness. This study will use both the ESI and EPQ to assess ES to try to build on previous research and evaluate the boundaries of both measures.

\section{Method}

\section{$\underline{\text { Participants }}$}

The sample consisted of 120 graduate students at a mid-sized university located in the southeastern United States. 110 participants (91.7\%) were employed and 10 (8.3\%) were either not currently employed or did not receive benefits from their employer. Nonemployed or non-benefit receiving participants were excluded from all analyses. Of the remaining participants, $74(67.3 \%)$ were employed full time while $36(32.7 \%)$ were employed part time. The mean job tenure was 34.96 months $(S D=36.07)$. Thirty-eight subjects $(34.5 \%)$ were employed in education, $12(10.9 \%)$ in service jobs, $8(7.3 \%)$ in finance, insurance or real estate, $8(7.3 \%)$ manufacturing, $4(3.6 \%)$ in public administration, $3(2.7 \%)$ in retail, $2(1.8 \%)$ in agriculture, forestry and fishing, $2(1.8 \%)$ in utilities, $1(1 \%)$ in transportation, $1(1 \%)$ in communication, and $31(28.2 \%)$ in other industries. Due to the public nature of the survey administration and potential confidentiality concerns by subjects, only the above demographic information was collected. 


\section{$\underline{\text { Measures }}$}

\section{Equity Sensitivity Instrument}

The ESI is a forced-choice questionnaire developed by Miles et al. (1989) that requires participants to allocate 10 points each to five pairs of statements. For example, "It would be more important for me to (a) get from the group; (b) give to the group." Based on the recommendation of Allen et al. (2003), a scale score was calculated by summing the points allocated to the Benevolent questions. In this way, ES is treated as a continuum of scores instead of three broad categories of people. ESI scores ranged from 15 to 48 $(M=28.26, S D=5.8)$. Consistent with reliabilities reported in earlier research the Cronbach's alpha was .81.

\section{Equity Preference Questionnaire}

The EPQ is a 16 -item 5-point Likert-type scale developed by Sauley and Bedeian (2000) with response options ranging from Strongly disagree to Strongly Agree. For example, one question reads "Even if I received low wages and poor benefits from my employer, I would still try to do my best at my job." Similar to the ESI, the EPQ was scored by summing the answers to all the scale questions (reverse scoring the negatively worded items) and this scale score was used for further analysis. EPQ scores ranged from 43 to $80(M=68.68, S D=6.94)$. Consistent with reliabilities reported in earlier research the Cronbach's alpha was .80 .

\section{Benefit Satisfaction}

Satisfaction with benefits was measured using a modified version of Hart and Carraher's (1995) survey assessing benefits satisfaction. There are 4 questions in the measure. The first two, 7-point Likert-type response items, measure benefit satisfaction. The third question, also a 7 point Likert-type response item, measures how easily benefits can be replaced. A fourth Likert-type response item assessed benefits importance. The four items were summed to form an overall benefits satisfaction scale score, which was used for further analysis. Benefits satisfaction scores ranged from 9 to 25 ( $M=18.71, S D=3.10)$. Cronbach's alpha was .63. Though for this sample Cronbach's alpha is low, other studies have shown more acceptable reliabilities. For example, Weathington and Tetrick (2000) reported reliabilities ranging from .79 to .90.

\section{Benefits Estimation Inaccuracy}

Benefits estimation inaccuracy was measured using a question adapted from Hart and Carraher (1995): "What percentage of your salary would you guess your benefits package is worth?" This number was then compared to the Bureau of Labor Statistics (BLS) estimates of the actual amount that individuals across the United States pay towards their benefits. The absolute difference between these two numbers was then reported as the inaccuracy of benefits estimation. While the BLS estimate will not be 
accurate for specific employees it is hoped that any resulting errors will be random and even out across participants.

\section{Results}

Descriptive statistics and correlations are presented in Table 1.

Table 1

Descriptive Statistics and Intercorrelations Between the ESI, EPQ, Benefits Satisfaction and Estimation Accuracy

\begin{tabular}{|c|c|c|c|c|c|c|}
\hline & $M$ & $S D$ & ESI & EPQ & $\begin{array}{l}\text { Benefits } \\
\text { Satisfaction }\end{array}$ & $\begin{array}{l}\text { Estimation } \\
\text { Inaccuracy }\end{array}$ \\
\hline ESI & 28.26 & 5.80 & -- & $.365^{\star *}$ & $.283^{* *}$ & $-.204^{*}$ \\
\hline EPQ & 68.68 & 6.94 & & -- & 0.125 & -0.002 \\
\hline $\begin{array}{l}\text { Benefits } \\
\text { Satisfaction }\end{array}$ & 18.71 & 3.10 & & & -- & $-.424^{\star \star}$ \\
\hline $\begin{array}{l}\text { Estimation } \\
\text { Accuracy }\end{array}$ & 14.63 & 9.51 & & & & -- \\
\hline
\end{tabular}

Hypothesis 1 stated that benevolents would be more inaccurate in their benefits estimations than sensitives and entitleds. The BLS reports that the average cost of benefits for an employer is $30.2 \%$. Each participant's estimate was subtracted from thirty percent and converted to an absolute value such that higher values equal less accurate estimations. Based on hypothesis 1 we expected the ESI and EPQ to be positively correlated with benefits estimation inaccuracy as higher estimation values would be associated with higher scores on the ES continuum (e.g. benevolents). However, the ESI was significantly negatively correlated with benefits estimation at the .05 level, $r=-.204$. The EPQ was not significantly correlated with estimation accuracy, $r$ $=-.002$. To evaluate the relationship between each measure of ES and benefit estimation inaccuracy (while controlling for the other), a regression analysis was run including both the ESI and EPQ as predictors of benefits estimation inaccuracy. Results (located in Table 2) show that the ESI is a significant predictor of benefits estimation inaccuracy while controlling for the EPQ, $\beta=-.384(p<.05)$. Thus, hypothesis 1 (that equity benevolents would less accurately estimate employer contributions to benefit costs) was not supported. This analysis was rerun without using absolute values and the results followed the same pattern. 
Table 2

Summary of Regression Analysis for Variables Predicting

Benefit Estimation Accuracy and Benefit Satisfaction

\begin{tabular}{llll}
\hline \multicolumn{1}{c}{ B } & SE B & $\beta$ \\
\hline $\begin{array}{l}\text { Benefit } \\
\text { Estimation } \\
\text { Accuracy }\end{array}$ & & & \\
ESI & -384 & 0.159 & $-.234^{*}$ \\
EPQ & 0.114 & 0.133 & 0.083 \\
$\begin{array}{l}\text { Benefit } \\
\text { Satisfaction }\end{array}$ & & & \\
ESI & 0.146 & 0.051 & $.274^{*}$ \\
$E P Q$ & 0.001 & 0.043 & 0.025 \\
${ }^{*} p<.05$ & & &
\end{tabular}

Hypothesis 2 posited that equity entitleds would be less satisfied with their benefits than equity sensitives and benevolents. To test this hypothesis, correlations were run on both ES measures, the ESI and EPQ, and overall benefit satisfaction. The correlation between the ESI and overall benefits satisfaction yielded a significant positive correlation at the .01 level of .28, while the correlation between the EPQ and overall benefits satisfaction yielded a nonsignificant correlation of .13. To evaluate the relationship between each measure of ES and benefit satisfaction (while controlling for the other), a regression analysis was run including both the ESI and EPQ as predictors of benefits satisfaction. Results show that the ESI is a significant predictor of benefits satisfaction while controlling for the EPQ, $\beta=.146(p<.05)$. Thus, hypothesis 2 was supported for the ESI such that equity entitleds were less satisfied with their benefits.

\section{Further Analyses}

Due to the inconsistent results found across the ESI and EPQ, the reliability of both measures were calculated and then compared using Feldt's (1980) test of dependent reliabilities. Feldt's test utilizes the correlation between two measures obtained during the same test administration. The reliability of the two measures are compared to determine whether or not they are significantly different. Table 1 shows that $r_{\times 1 \times 2}=.365$, 
and the reliabilities of the ESI and EPQ are .81 and .80 respectively, $\mathrm{W}=1.03, p>.05$. This result suggests that both measures are equally reliable.

The dimensionality of both measures was also assessed utilizing an exploratory factor analysis. For the $\mathrm{ESI}$, only one factor was identified with eigenvalues above one, explaining $57 \%$ of variance. However, the EPQ scale questions loaded onto four factors, which explained $57 \%$ of the variance (See Appendix).

\section{Discussion}

Analyses provided mixed support for the proposed hypotheses. It does appear, as measured by the ESI at least, that the inaccuracy of benefits estimation and satisfaction with benefits varies with one's position on the ES spectrum. Specifically, entitleds are least satisfied with their benefits while benevolents are the most satisfied, with sensitives falling in between. Interestingly, however, benevolents more accurately estimate their benefits. This finding is interesting in that past research on ES indicated that benevolents are less concerned with external rewards. Yet, this study shows that despite this preference for internal rewards (i.e. recognition and achievement), those higher on the ES spectrum still pay attention to external outcomes, such as how much money their employer contributes towards their benefits. It may be the case that benevolents are more likely than entitleds to give their employer credit for the money spent on their behalf. Entitleds may discount or ignore employer costs and focus instead on their own costs. Further research needs to clarify this finding.

That an individual's tolerance for over- or under-reward manifests itself in attitudes toward benefits has clear implications for benefit administration. The BLS estimated in 2008 that benefits make up, on average, $30 \%$ of an employees' total compensation (significantly more in some organizations). Therefore, if employees are dissatisfied with benefits, then this money is not being fully utilized. It might behoove companies to put a line item on every paycheck that explicitly states how much the company paid towards an employee's benefits for that pay period. In this way, the company's contribution is more salient and thus may be put to better use. If entitleds prefer or tolerate situations where their outputs exceed their inputs, then adding a benefits line item may increase the output they believe they are receiving and thus may increase satisfaction with benefits.

Another possible avenue for future ES research relates to the relationship between ES typology outcome preference and Herzberg's Motivation-Hygiene factors. Since its introduction in 1959, Herzberg's theory has received scant positive support (see Vroom, 1964; Hardin, 1965). However, Herzberg's theory may provide some insight into the differences between individuals on the ES spectrum. For example, under Herzberg's theory, money is viewed as a hygiene factor. Thus, if an individual perceives that they are not receiving the salary they deserve, they will become dissatisfied. The same may be said for benefits. However, it may be that one's position on the ES spectrum determines whether or not they view benefits as a hygiene factor. Thus, for someone lower on the ES spectrum, benefits may be an entitlement and as such would be a 
hygiene factor. However, as one's position on the spectrum increases, it may be that their perception of what is an entitlement (e.g. hygiene factor) changes, and thus their relative level of satisfaction or dissatisfaction would change accordingly. Future research should examine if ES theory has any moderating effect on the relationship between Herzberg's Motivation-Hygiene factors and organizational outcomes.

Additionally, the finding that the ESI is composed of one factor while the EPQ is comprised of four suggests that the ESI is the more appropriate global measure of ES. A review of the four dimensions identified in this study suggests that, instead of global $E S$, the EPQ is actually measuring identifiable subfacets related to entitlement (Factor 1 ), energy (Factor 2), extra role behavior (Factor 3 ) and desire to "do your best" (Factor 4). Future research should investigate these facets and evaluate their usefulness for research and relation to global ES. Given that a) the ESI and EPQ have acceptable and comparable reliabilities, b) the correlation between them is low for two measures purported to measure the same thing, c) the ESI is unidimensional but the EPQ is not.

\section{Limitations}

Several aspects of the current study should be considered when judging the soundness of the above conclusions. One is the relatively low reliability demonstrated in this sample by Hart and Carraher's (1995) benefits measure. A Cronbach's alpha of .63 is poor, thus any conclusions based on it should be interpreted with caution, as reliability is a prerequisite for validity. If the question "How important is your benefits package to you" was deleted from the measure, Cronbach's alpha would rise to .72, which is better but still undesirably low. One possible explanation for why this item reduces reliability is that even though it appears face valid, the importance an individual places on benefits may not be related to how satisfied they actually are with those benefits. Alternatively, differences in the importance attached to individual benefits may limit the reliability for a global question of benefit important such as this one. This may relate back to Weathington and Tetrick's (2000) finding that some benefits are seen as entitlements while others are not. Perhaps people may see their overall benefits package as an entitlement, and as such, not view benefits as being an important part of their compensation. This sense of entitlement may then cause one's perceived importance of their benefits to be unrelated to one's satisfaction with their benefits. Or, it could be that the individual nature of benefit perception might be the issue. For example, medical insurance is not viewed the same as a retirement plan (Weathington, 2008). Weathington and Tetrick (2000) found alphas ranging from .79 to .90 when using these items and replacing "benefit package" with the names of specific benefits.

Another potential confound is the broad measure used to assess the accuracy of benefits estimation. Since subjects were employed at multiple organizations, it was necessary to use a generalized standard with which to compare a subject's inaccuracy. However, the bureau of labor statistics figure of $30.2 \%$ is a measure of central tendency and as such represents more than some companies put towards their benefits but less than others. The inexact nature of the statistic makes it difficult to determine exactly how much each individual erred in their estimation. While the over- and under-estimations 
may have averaged out across the entire sample, conducting this study in a single organization where the company's exact contribution towards benefits is known would provide less suspect findings.

Finally, common method variance could account for the observed relationships among the variables. Common method variance is a methodological artifact that is defined as variance that is attributed to multiple constructs being measured using the same method (i.e. self-report questionnaires) rather than actual covariance between the constructs (Podsakoff, MacKenzie, Lee and Podsakoff, 2003; Schmitt \& Ryan, 1993). For example, all the data in the current study were collected using self-report Likert-type questionnaires. Given that common method variance can inflate or obscure actual correlations between measures (Podsakoff et al.), it is possible the observed relationships between the constructs (e.g. ES, benefit estimation inaccuracy, and benefit satisfaction) were in some way altered by the common measurement method.

\section{Conclusion and Implications}

The ESI appears to be a more psychometrically sound measure of global ES than the EPQ. While the ESI appears to be measuring only one construct (presumably ES), the EPQ appears to be measuring multiple constructs. Further research on the ESI could focus on sample specific characteristics, such as race, gender, or other demographic differences. Regarding the EPQ, more scrutiny is needed to determine exactly what it is measuring and if, ultimately it is an appropriate and useful psychometric tool.

Results suggest that there is a relationship between an individual's position on the equity sensitivity spectrum and satisfaction with benefits. The practical implications of this is that assessing an employee's ES may allow a company to construct an intervention aimed at altering the attitudes of the employee, specifically employees low on the ES spectrum. One possible intervention could include inserting a line item on every employee paycheck that states the value of the company's contribution. In this way, the money the company puts towards benefits will be better utilized. Further research could focus on the extent to which organizational characteristics, such as perceived organizational justice, affect the relationship between ES and benefits satisfaction. Samples should be taken from single organizations so that more exact benefits information can be gleaned.

\section{References}

Adams, J. S. (1965). Inequity in social exchange. In Berkowitz, L. (Ed.) Advances in experimental social psychology (Vol. 2, pp. 267-299). New York, Academic Press.

Allen, R. S., Biderman, M. D., \& White, C. S. (2004). Emotional intelligence and its relation to equity sensitivity and response to under-reward situations. The Journal of Behavioral and Applied Management, 5(2), 114-136.

Allen, R. S., Takeda, M., \& White, C. S. (2005). Cross-cultural equity sensitivity: a test of differences between the United States and Japan. Journal of Managerial Psychology, 20(8), 641-662. 
Allen, R. S., \& White, C. S. (2002). Equity sensitivity theory: a test of responses to two types of under-reward situations. Journal of Managerial Issues, 14(4), 435-451.

Arnold, T., \& Spell, C. S. (2006). The relationship between justice and benefits satisfaction. Journal of Business and Psychology, 20(4), 599-620.

Blakely, G. L., Andrew, M. C., \& Moorman, R. H. (2005). The moderating affects of equity sensitivity on the relationship between organizational justice and organizational citizenship behaviors. Journal of Business and Psychology, 20(2), 259-273.

Bureau of Labor Statistics. (n.d.). 2008 employer cost for employee compensation survey. Retrieved January 17, 2009, from http://www.bls.gov/news.release/ecec.nr0.htm.

Byrne, M. (2006). The implications of Herzberg's "Motivation-Hygiene" theory for management in the Irish health sector. The Health Care Manager, 25(1), 4-11.

Feldt, L. S. (1980). A test of the hypothesis that Cranach's alpha reliability coefficient is the same for two tests administered to the same sample. Psychometrika, 45(1), 99-105.

Foote, D. A., \& Harmon, S. (2006). Measuring equity sensitivity. Journal of Managerial Psychology, 21(2), 90-108.

Greenberg, J. (1987). A taxonomy of organizational justice theories. Academy of Management Review, 12, 9-22.

Hardin, E. (1965). Perceived and actual changes in job satisfaction. Journal of Applied Psychology, 49(2), 363-367.

Hart, D. E., \& Carraher, S. M. (1995). The development of an instrument to measure attitudes towards benefits. Educational and Psychological Measurement, 55(3), 480-484.

Herzberg, F. (1966). Work and the nature of man. Cleveland: World Publishing Company.

Messmer, M. (2006). Benefits: gain a competitive edge with offerings employees want. Strategic Finance, 88(5), 8-10.

Miles, E. W., Hatfield, J. D., \& Huseman, R. C. (1989). The equity sensitivity construct: potential implications for worker performance. Journal of Management, 15(4), 581-588.

Miles, E. W., Hatfield, J. D., \& Huseman, R.C. (1994). Equity sensitivity and outcome importance. Journal of Organizational Behavior, 15(7), 585-596.

Podsakoff, P. M., MacKenzie, S. B., Lee, J. Y., \& Podsakoff, N. P. (2003). Common method biases in behavioral research: A critical review of the literature and recommended remedies. Journal of Applied Psychology, 88(5), 879-903.

Restubog, S. L. D., Bordia, P., \& Tang, R. L. (2007). Behavioral outcomes of psychological contract breach in a non-western culture: the moderating role of equity sensitivity. British Journal of Management, 18, 376-386.

Rousseau, D. M. (1989). Psychological and implied contracts in organizations. Employee Responsibilities and Rights Journal, 2(2), 121-139.

Sauley, K .S., \& Bedeian, A. G. (2000). Equity sensitivity: construction of a measure and examination of its psychometric properties. Journal of Management, 26, 885-910.

Shore, T. H. Equity sensitivity theory: do we all want more than we deserve? Journal of Managerial Psychology, 19(7), 722-728. 
Schmit, M. J., \& Ryan, A. M. (1993). The Big Five in personnel selection: Factor structure in applicant and nonapplicant populations. Journal of Applied Psychology, 78, 966-974.

Vroom, V. H. (1964). Work and motivation. New York, NY, Wiley.

Weathington, B.L. (2008). Income level and the value of non-wage employee benefits. Employee Responsibilities and Right Journal, 20, 291-300.

Weathington, B. L., \& Jones, A. P. (2006). Measuring the value of non-wage employee benefits: building a model of the relationship between benefit satisfaction and benefit value. Genetic, Social, and General Psychology Monographs, 132(2), 292-328.

Weathington, B. L., \& Tetrick, L. E. (2000). Compensation or right: an analysis of employee "fringe" benefit perception. Employee Responsibilities and Rights Journal, 12(3), 141-162.

Wheeler, K. G. (2007). Empirical comparison of equity preference questionnaire and equity sensitivity instrument in relation to work outcome preferences. Psychological Reports, 100, 955-962.

Wilson, M., Northcraft, G. B., \& Neale, M. A. (1985). The perceived value of fringe benefits. Personnel Psychology, 38, 309-320

Yamaguchi, I. (2003). The relationship among individual differences, needs and equity sensitivity. Journal of Managerial Psychology, 18(4), 324-344. 


\section{Appendix}

Rotated Factor Pattern: Equity Preference Questionnaire

Item

I

I

II III

IV

1. I prefer to do as little as possible at work while getting as much as I can from my employer.

$\begin{array}{llll}\underline{0.59} & 0.00 & 0.17 & 0.08\end{array}$

2. I am most satisfied at work when I have as little to do as possible.

$\begin{array}{llll}0.35 & \underline{-0.37} & 0.22 & -0.15\end{array}$

3. When I am at my job, I think of ways to get out of work.

$\begin{array}{llll}0.55 & -0.17 & 0.06 & 0.02\end{array}$

4. If I could get away with it, I would try to work just a little bit slower than the boss expects.

$\underline{0.53} \quad-0.13 \quad-0.01 \quad-0.03$

5. It is really satisfying to me when I can get something for nothing at work.

$\begin{array}{llll}\underline{0.46} & 0.05 & 0.28 & -0.10\end{array}$

6. It is the smart employee who gets as much as he/she can while giving as little as possible in return.

$\begin{array}{llll}0.73 & -0.11 & -0.08 & 0.00\end{array}$

7. Employees who are more concerned about what they can get from their employer rather than what they can give to their employer are the wise

$\begin{array}{llll}\underline{0.74} & 0.15 & -0.19 & 0.16\end{array}$
ones.

8. When I have completed my task for the day, I help out other employees who have yet to complete their $\begin{array}{llll}0.11 & 0.09 & \underline{0.32} & 0.23\end{array}$ tasks.

9. Even if I received low wages and poor benefits from my employer, I would still try to do my best at my job.

10. If I had to work hard at my job all day, I would probably quit.

$\begin{array}{llll}0.15 & -0.38 & \underline{0.40} & -0.17\end{array}$ 
Item

11. I feel obligated to do more than I am paid to do at work.

$\begin{array}{llll}0.01 & -0.04 & 0.10 & \underline{0.42}\end{array}$

12. At work, my greatest concern is whether or not I am doing the best job I can.

$\begin{array}{llll}0.12 & -0.28 & 0.01 & \underline{0.57}\end{array}$

13. A job which requires me to be busy during the day is better than a job which allows me a lot of loafing.

$\begin{array}{llll}-0.14 & \underline{-0.71} & 0.25 & 0.08\end{array}$

14. At work, I feel uneasy when there is little work for me to do.

$\begin{array}{llll}0.10 & \underline{-0.66} & -0.11 & 0.11\end{array}$

15. I would become very dissatisfied with my job if I had little or no work to do.

$\begin{array}{llll}0.07 & \underline{-0.71} & -0.13 & 0.03\end{array}$

16. All other things being equal, it is better to have a job with a lot of duties and responsibilities than one

$\begin{array}{llll}0.16 & \underline{-0.65} & -0.11 & 0.01\end{array}$ with few duties and responsibilities. 